\title{
Name-display Feature for Self-disclosure in an Instant Messenger Program: A Qualitative Study in Taiwan
}

\author{
Pao-Nan Chou and Wei-Fan Chen \\ Penn State University, State College, PA, USA
}

pxc251@psu.edu; weifan@psu.edu

\begin{abstract}
In Taiwan, instant messenger usage has become the third most frequently engaged online activity following web cyberspace's web surfing and e-mail. Among different kinds of instant messengers, Windows Live Messenger (WLM) is the most popular software program. The purpose of this study is to explore users' name-display behaviors on WLM from a self-disclosure perspective. The study employs phenomenological methodology to elicit lived experiences of using the name-display feature in the WLM. Twelve subjects, 3 women and 9 men, participated in this study. From 12 verbatim transcripts, after identifying significant statements, clustering the formulated meanings resulted in 9 themes. The key findings are: (1) Self-disclosure behavior exists in the name-display feature in the instant messenger; (2) Participants revealed disclosure topics to achieve self-expression purpose; (3) Social support occurred when participants identified other online users' nicknames; (4) Participants revealed their nicknames for social validation; (5) Self-disclosures would not reveal messages that provoke threats; (6) In order to create a certain desired impression, participants would manipulate the disc losure messages; and (7) Silent self-disclosure with verbal forms is participants' preference in cyberspace.
\end{abstract}

Keywords: Instant messenger, Self-disc losure, Phenomenological study, Online social support

\section{Introduction}

Today, with high-speed network technology available, cyberspace has been a communication center in which people can distribute useful information, share valuable know ledge, receive training or education, conduct business transactions, build a social relationship, and so forth (Kang, 2007; Moore, 2005; Qian \& Scott, 2007). Cyberspace yields dramatic impact on human beings' daily lives and plays an important role in the modern society (Cheuk, 2007).

In Taiwan, a survey (Yam Portal, 2005) showed that "instant messenger" (IM) usage has become the third most frequently accessed online activity following cyberspace's web surfing and e-mail.

Material published as part of this publication, either on-line or in print, is copyrighted by the Informing Science Institute. Permission to make digital or paper copy of part or all of these works for personal or classroom use is granted without fee provided that the copies are not made or distributed forprofit or commercial advantage AND that copies 1) bear this notice in full and 2) give the full citation on the first page. It is permissible to abstract these works so long as credit is given. To copy in all other cases or to republish or to post on a server or to redistribute to lists requires specific permission and payment of a fee. Contact Publisher@InformingScience.org to request redistribution permission.
The report also indicated 66 percent of online users use at least one type of IM program to communicate with friends. Considering the types of IM, Windows Live Messenger (WLM) is the most popular software program (Yu, 2003). According to Microsoft Corporation( $($ in Taiwan (MSN Network in Taiwan, 2006), the number of WLM users reached 7.5 million before the end of 2006. Taiwanese people who used WLM spent ap- 
proximate ly 1.2 hours in the WLM system every day. Recently, in order to increase productivity, numerous business companies and government agencies prohibited employees from using WLM in their workplaces (Wu, 2007). For the situations described above, therefore, examining the phenomena of the IM usage can facilitate understanding on users' behaviors.

IMs, such as WLM, allow users to send real time messages to their online friends, who are listed on a friend list. Users add their friends' e-mail addresses to the list so that two correspondents can successfully chat via cyberspace. A name-display is one feature on an IM screen. Users can use it to self-define their nicknames which will be displayed in online friends' IM lists. For example, once one side defines the nickname, other side can see it appear in the IM's screen. Based on first-hand experiences, some users frequently change their nicknames which represent specific meaning; some others do not. Whether or not the chosen name-display reflects special psychological factors is worthy of exploration.

In the literature, the IM use has been applied to different activities. In the field of English education, for the purpose of enhancing students' learning outcomes, Tai (2007) integrated WLM into English learning curriculum. In the domain of forensic science, Van Dongena (2007) attempted to find crime evidence by analyzing various features of WLM. In the field of business, Cameron and Webster (2005) investigated IM's impact on employees' workplace performance. In the area of health education, Cheuk and Chan (2007) found that IM use affects students' academic performance. From the computer-mediated communication perspective, Leung (2004) reported that self-disc losure was signif ic antly related to IM usage. However, of those studies focusing on IM, few adopted a qualitative methodology.

Compared to the application of IM use, the number of studies considering the name-display feature in the programs is sparse. Grinter and Palen (2002) reported that teen users changed their nicknames as a polite justification so that their online friends could easily identify their unavailability. Smale and Greenberg (2005) employed a specific program to record 444 users' nickname changes processed in three weeks. They found that most of participants frequently changed their nicknames and a relationship existed between age and the frequency of nickname changes. Furthermore, constantly changed nicknames fell into three categories: identification, information about self and broadcast message. However, for the previous two studies, the researchers did not explore the name-display feature from a psychological perspective.

A feature in the Bulletin Board System (BBS) is extremely similar to the name-display feature in the IM program. In addition to users' IDs, their self-defined nicknames also appear on the BBS. Previous research showed that nickname-display behavior on a BBS relates to self-disclosure (Hsueh, 2001). However, whether or not name-display behavior of IM relates to self-disc losure remains unknown. Therefore, this study attempts to explore users' name-display behavior in the IM programs from a self-disclosure perspective.

\section{Theoretical Framework}

\section{Self-disclosure}

The concept of self-disclosure is often defined as "...what individuals verbally reveal about themselves to others (including thoughts, feelings, and experiences)..." (Derlega, 1993, p.1). Although verbal statements tend to fall into oral communication, self-disclosure also contains written representations. Furthermore, the number of people to whom a person self-discloses personal information must be at least one. For instance, keeping private journals can not be self-disclosure (Omarzu, 2000). According to Derlega and Grzelak (1979), the motives behind self-disclosure behavior are: expression, self-clarification, soc ial validation, relationship development, and social control. Some experts even regard self-disclosure behavior as an indicator of health (Derlega, 1993; 
Doster, 1979; Omarzu, 2000). Past research showed that self-disc losure closely related to variables of: gender, race, nationality, martial status, and stress (Derlega, 1993; Jourard, 1971).

\section{Self-disclosure in Cyberspace}

Since the Internet contains numerous media forms, the concept of self-disclosure has been applied to examine online users' behaviors (Joinson, \& Paine, 2007). In order to explore the relationship between anonymity and self-disc losure on weblogs, Qian and Scott (2007) surveyed weblog users' opinions. The results showed that visual anonymity (i.e. photos) did not relate to self-disclosure. In contrast, discursive anonymity (i.e. pseudonym or real name) associated with self-disclosure. Joins on (2001) reported that if the researcher revealed personal information, such as curriculum vitae, to participants in an Internet-based survey which included six open-ended questions, the participants would reciprocally disclose an great amount information about themselves. Barak and Gluck-Ofri (2007) explored the effect of self-disclosure on different types of online forums. They found that self-disclosure in emotional support forums is more frequent than in neutral discussion forums and the reciprocal behavior of self-disclosure also existed in this type of online forums. In the Dietz-Uhler et al. 's (2005) study, the patterns of self-disclosure occurred in a synchronous chat room when students engaged in discussing one specific topic. Tichon and Shapiro (2003) found that self-disclosure served as a social support function in an e-mail listserv. Leung (2004) indicated that chat in an IM context closely related to depth of comment and intent for self-disclosure. From the above related literature, significant evidence confirms the role of self-disclosure in cyberspace regardless of the specific employment of various communication media.

Background information and theoretical framework discussed earlier lead to the main research question of this study:

$R Q$ - What are Taiwanese' lived experiences for using the name-display feature in an instant messenger program (i.e. WLM)?

\section{Method}

\section{Sampling}

This study uses purposeful sampling, which focuses on information-rich cases, in order to obtain in-depth information on name-display. For this reason, all participants were those who frequently use the name-display feature to change their nicknames in the WLM program.

Twelve subjects, 3 women and 9 men, partic ipated in this study. The total sample size satisfies the phenomenology requirement in which at least six individuals who all have experienced the phenomenology are interview subjects (Morse, 1994). All participants were Taiwanese residents and currently not school students. The average age was 26 years $(\mathrm{SD}=2.6)$. The majority had a university education (83\%). Only one participant was married. The average number of years using WLM was $3.5(\mathrm{SD}=1.3)$. Time spent accessing the WLM system was 6.3 hours $(\mathrm{SD}=1.6)$ per day and approximately 6 days $(\mathrm{SD}=0.9)$ per week.

\section{Research Design}

This study employed a phenomenological methodology to explore users' online behaviors in order to obtain more in-depth understanding of any possible experiences users might encounter in the WLM program. According to van Manen (1997), "the aim of phenomenology is to transform lived experience into a textual expression of its essence..." (p. 36). Van Manen further claimed that “... the task of phenomenological research and writing: to construct a possible interpretation of the nature of a certain human experience" (p. 41). The purpose of this study fits well with van Manen's statement because it seeks to understand users' lived experiences for using the name-display fea- 
ture in the WLM program and further interpret their perceptions of frequent engagement in the name-display feature.

Based on literature review and the researcher' personal experiences, a semi-structured interview guide was developed (See Appendix). With regard to the design of interview process, this study applies Seidman's (2006) three series of phenomenological interviewing: focused life history, the details of present lived experience, and reflection on the meaning of experience with minor modification. In order to match with participants' schedule, the three series of interviewing were condensed into a 90-minute interview with each research participant.

After data collection, Moustakas's (1994) method of phenomenological analys is was employed to analyze all written transcripts. First, significant phrases or sentences were identified (pre liminary grouping). Second, meanings were formulated from significant phrases or sentences (clustering of invariant meaning units). Third, the formulated meanings are clustered into different themes (searching for themes). Finally, exhaustive descriptions of each theme and overarching interpretation of essences of the experiences were provided (composite textural-structural descriptions).

\section{Procedure}

Data collection of this study occurred in three stages. First, a two-week manual observation of an online friend list (116 users) identified 15 users who frequently changed their nicknames. Second, after an approach to those users to obtain permissions for this study, they all agreed that their nicknames could be recorded during the upcoming one-month period. Third, a one-month observation stage recorded all nicknames through a programming tool. Finally, after collecting the nickname change occurrences, each individual interview time was scheduled. Interviews occurred over three weeks. However, during this time, for some reason, three participants resigned from the study. At a scheduled time, each interviewee responded to a voice message via an online talking feature in the WLM program. Interviewees all agreed to recording of the ir conversation contents by recording software. The interviews provided an opportunity to obtain participants' background information.

\section{Validity and Reliability}

In order to increase validity and reliability of this study, a number of techniques were employed. For validity, Creswell (2007) considered that qualitative researchers should take at least two of the following methods to confirm validity: prolonged engagement, triangulation, peer review or debriefing, negative case analys is, clarif ication of researcher bias, member checking, thick description, and external audits. Of those techniques, this study conducted triangulation, peer review, and member checking. In triangulation, multiple sources, such as online observations and interviews, corroborate evidence. For peer review, several qualitative research course colleagues continuously questioned research design to increase the research quality. As for member checking, once interpretative data had been obtained, some participants reviewed data second time to validate the findings.

Concerning reliability, in order to confirm the accuracy of interview contents, after transcribing the recordings, the second interviewer checked the transcription by reviewing the recordings. In addition, since the original transcriptions were written in Chinese, a Taiwanese student whose college major is English education confirmed the accuracy of the final results' translations.

\section{Researcher Identity}

With respect to personal experiences, before conducting this study, the researcher had used the WLM program more than four years. WLM allows sending messages to friends and family members in real time. Seldom was name-display feature used. The nickname in the WLM only 
showed the user's first name. When logging on the WLM system each time, the researcher found that while online friends frequently changed their nicknames, others retained their or iginal self-defined nicknames. Of those nicknames, not all meanings of nicknames were recognizable. For example, one online friend defined his nickname as "A.A.A (Addiction Alcohol Anonymous)."

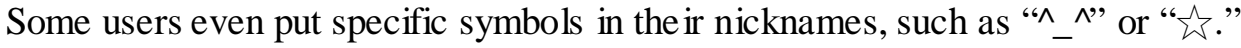

\section{Results}

During a one-month online observation, users' self-defined nicknames were recorded. Table1 shows how often online users changed their nicknames in one month.

Table 1. Change Rate for Nicknames

\begin{tabular}{lllllll}
\hline Users & Gender & Age & $\begin{array}{l}\text { Rate of } \\
\text { Change }\end{array}$ & $\begin{array}{l}\text { Average } \\
\text { year using } \\
\text { WLM }\end{array}$ & $\begin{array}{l}\text { Time spent } \\
\text { staying in WLM } \\
\text { system per } \\
\text { day(hour) }\end{array}$ & $\begin{array}{l}\text { Time spent staying in } \\
\text { WLM system per } \\
\text { week(day) }\end{array}$ \\
\hline P1 & Male & 24 & 15 & 5 & 8 & 5 \\
P2 & Female & 21 & 18 & 2 & 7 & 7 \\
P3 & Female & 28 & 22 & 3 & 6 & 5 \\
P4 & Male & 25 & 20 & 4 & 5 & 7 \\
P5 & Male & 24 & 25 & 6 & 7 & 5 \\
P6 & Male & 31 & 21 & 5 & 3 & 7 \\
P7 & Female & 28 & 11 & 2 & 7 & 5 \\
P8 & Male & 26 & 14 & 3 & 9 & 7 \\
P9 & Male & 25 & 19 & 3 & 5 & 6 \\
P10 & Male & 28 & 15 & 2 & 7 & 5 \\
P11 & Male & 28 & 17 & 4 & 7 & 6 \\
P12 & Male & 27 & 19 & 3 & 5 & 5 \\
\hline
\end{tabular}

From Table1, by calculation, the average change rate is 18 . In other words, the high frequency indicates that each participant changed a nickname once every two days. Furthermore, regardless of the measurement type (i.e. hour or day), time spent staying on the WLM system is extremely long. When asked about this issue, most participants responded that the IM automatically logs onto the server system when the computer runs its operational system (e.g. Windows). They remain online until the computer is turned off.

From 12 verbatim transcripts, after identifying significant statements, clustering the formulated meanings resulted in 9 themes. Table 2 summarizes the main idea of 9 themes. 
Table 2. Main Ide as of Themes

\begin{tabular}{|l|l|}
\hline \multicolumn{1}{|c|}{ Theme } & \multicolumn{1}{c|}{ Main Idea } \\
\hline 1. Feature adoption & Why did participants adopt name-display feature? \\
\hline 2. A hint for someone else & $\begin{array}{l}\text { Participants provided a hint for specific online users by } \\
\text { defining unique nicknames }\end{array}$ \\
\hline 3. A warning signal for myself & $\begin{array}{l}\text { Participants often defined nicknames for the warning pur- } \\
\text { pose }\end{array}$ \\
\hline 4. Broadcasting special messages & $\begin{array}{l}\text { Participants defined the ir nicknames by broadcasting spe- } \\
\text { cial messages }\end{array}$ \\
\hline 5. Showing personal feelings & $\begin{array}{l}\text { Participants defined the ir nicknames by showing personal } \\
\text { feelings }\end{array}$ \\
\hline 6. Tone decided by mood & $\begin{array}{l}\text { Mood influenced the tone of participants' self-defined } \\
\text { nicknames }\end{array}$ \\
\hline 7. Polarized reaction & Most participants were surprised with their change rates. \\
\hline 8. Caring about online friends & Participants paid attention to online friends' nicknames. \\
\hline 9. Behavior in real life & $\begin{array}{l}\text { Participants would not actively reveal personal feelings to } \\
\text { friends in real life. }\end{array}$ \\
\hline
\end{tabular}

\section{Theme 1: Feature Adoption}

Most participants discovered the name-display feature by themselves. They began to use it after installing the IM program. P8 stated, "When I installed that (instant messenger), I tried many features it has. The name-display feature is one of the frequently used features for my instant messenger use." A female participant (P3) had already used a similar feature in a software program so she easily identified this feature. She said,

"I am a heavy BBS (Bulletin Board System) user. A feature in BBS is very similar to the name-display feature in WLM. I often use it to express my feeling on the BBS. Once I knew my instant messenger has this feature, I automatically adopted it."

A few participants expressed that their online friends influenced their adoption decision. P6 said, "The reason I use this feature is that one of my online friends asked me to define special nicknames. So doing allows them to recognize me quickly" Another (P12) responded to this issue with a serious tone:

"Initially, I did not use that feature at all. However, when more and more online friends adopted this feature, there is an unseen pressure on me. If I do not use that feature to express something, it seems to me that I will be behind the current trend. I do not want to be a boring guy."

One male participant adopted the feature from a comparative perspective. P10 said,

"Before using the name-display feature, I have used a blog to express my daily feelings for a long time. However, keeping a journal in blog is not as easy as a changing nickname. Being a blogger, you should log in a system to edit entries, which means you should spend a long time organizing the entries." 


\section{Theme 2: A Hint for Someone Else}

In this theme, a few participants provided a hint for specific online users by defining unique nicknames. Interestingly, however, their targeted online friends could not identify what the nickname means. P1 once changed his nickname ("I don't know anything") for this purpose. He provided in-depth ins ight:

"The reason I changed the nickname is to provide a hint for my girlfriend. We have been dating four years. I am always the last one person who knows what happened to her. I can not figure out why she would rather tell her female friends. However, my girlfriend did not know what the nickname means."

In contrast, the person for whom P4 wanted to provide a hint is not a close friend. He disliked what his online friend did. He explained his defined nickname ("Don't go overboard"), "He (his online friend) is a liar. He has a love affair with his co-worker. His girlfriend is still unaware of his betrayal."

When asked if any online friends responded their nicknames, participants all answered "Yes." However, if the online friends are casual acquaintances, they bypassed the meaning of the nicknames.

\section{Theme 3: A Warning Signal for Myself}

Some participants often defined nicknames for the warning purpose. They were dissatisfied with some aspects of daily life or dis liked the ir friends' behavior. The nicknames serve as warning signals which discourage participants from engaging certain activities. P4 is a newspaper reporter with a defined nickname ("real reporter!") which expressed his feeling regarding the function of a reporter. He said, "My co-worker added strong bias to his writing. I would not want to be like that. Mis leading readers is not our job." P5 used his defined nickname ("my beer belly") to express his dissatisfaction. He stated, "My belly is like an inflated balloon. I should begin to exercise. I would not want to be a fat man." A female (P2) used the nickname ("Don't do again") to warn herself about a bad habit. She said:

"Like other adult females, I can not resist going shopping. When I see a suit of beautiful clothes or a pair of nice shoes, I will buy them. That means I am always in debt. I want to break this bad habit."

When online friends respond to participants' nicknames, informal discussion emerges. Discussion points center on solutions for the problems written in the nicknames. Participants stated that their online friends share personal experiences as suggestions.

\section{Theme 4: Broadcasting Special Messages}

Messages which participants want to broadcast can be categorized into three types: First, some participants enjoyed quoting phrases or sentences they saw in newspapers, books, and on TV news. They felt that the meaning of quotations makes sense to them. Defining nicknames as quotations they like can broadcast knowledge or information to their online friends. P4 just finished reading a bestselling book "The Kite Runner". He changed his nickname into a sentence ("You'll never learn anything of value from those bearded idiots") from this book. He wished his online friends could read that book. P5 often quotes sentences from articles in an online newspapers' website. He said, "Most of time, some interesting news would attracts my attention. I copy the sentence I like and paste it in my nickname feature. I want my online friends to know what happened recently." Since a voting rule in Taiwan was modified, P8 quoted a news headline in his nickname to inform his online friends. 
Second, other participants liked to quote song titles or lines actors said in movies. The purpose is to recommend that online friends should listen to certain music or watch targeted movies. P2 is a popular song fan. After listening to a good song, she would use her nickname to public ize that song. $\mathrm{P} 1$ watched a romantic movie with his girlfriend recently. One of his nicknames is a quotation from the movie. He said, "I love that movie so much. It really touches my heart. I want my online friends to know that the movie I saw was great."

The third type focuses on messages which participants were eager to broadcast to specific online friends. A distinguishing feature for those messages is that participants want to express their thanks or give their congratulations to specific online friends. One of P10's friends was to be married soon. He changed the messenger's nickname to convey heartfelt wishes to his friend. P3 also encountered the same situation. However, the words ("You got happiness") she put in her nickname carried special connotation. She was hoping for that kind of happiness (marriage) in the future. P12 once borrowed a book from his friend. He employed the nickname to give special thanks to his friend. He stated, "I knew my friend has that book. I did not want to spend money buying it. So, I am very thankful for his help."

Considering the first and second category discussed earlier, when participants' online friends respond to the ir nicknames, polarized discussion themes will form. For those who have experienced the situations described in the nicknames, they would share their opinions and feelings with partic ipants. Often, the discussion lasted longer. In contrast, for those who did not understand the meaning of nicknames, they only inquired as to the meaning from participants. No further discussion would result. As for the third category, only the people for whom participants wanted to thank responded to the nicknames. "You are welcome!" and "Thank you!" are two common phrases appearing in the discussion.

\section{Theme 5: Showing Personal Feelings}

Almost half of nicknames participants defined fall into this theme, including four sub-categories: personal opinions, complaints, recent activities and body condition. First of all, participants want to express personal opinions on how they judge everything around them. Based on participants' evaluation, those opinions carry strong sharp comments. P4 supported one political leader in Taiwan. Since the politic ian's recent wrongdoing disappointed him, his nickname was filled with negative comments. P1 bought a USB flash drive recently. He felt the product went behind his expectation. His nickname praised the product's utility. He said, "Because of cute appearance, I bought it. I never thought it would be so powerful." After watching a baseball game, P9 used his nickname to criticize the pitcher's bad performance. He said:

"He (the pitcher) has won five games in row. His secretweapon (cut ball) often strikes out the batters. The game I watched was so terrible. He did not strike out any batters. One batter was walked three times. He only pitched four innings. What happened to him?"

Another category is participants' complaints. The difference between complaints and personal opinions is that the nicknames participants defined are sentimental and the things participants complained happened in the workplace. With the nickname ("Idiot: How did you get driver license?") P2 defined her complaint of a rude driver. P7 could not deal with a heavy workload resulted in the nickname ("I'm fed up with your ugly tasks") which conveys her unpleasant feeling in the workplace. P3 felt one of the company's policies is unfair for her. The nickname ("Stupid rule. Why am I here?") carries a negative tone. She said, "This is my second year in this company. Nobody tells me this stupid rule. I think I should tell the boss about my situation."

The third type is recent activities participants have done or currently are involved in. The distinct feature in this sub-category is that people can easily identify what activities have completed/are doing/ will do. P6 often uses his nicknames to tell online friends about a recent schedule. For 
example, "I'm coming! Las Vegas." shows his future travel plan. "Ha! New Years final countdown at home" tells his completed task. Compared to P6, the nicknames P10 defined not only show activities he currently participated in, but also his mood toward the activities. For instance, "Ya...final hour in office" and "Crazy! My Excel can not work. Who can help me?" express his feelings during certain tasks.

The final one centers on the messages showing personal body condition. Participants hoped to shift their uncomf ortable feelings away from defined nicknames. In the workplace, P1 suspected that something is wrong with his body. The nicknames he defined contain several symptoms of his ill body. P9 made good use of his nicknames to express health status while working in an office. "Dizzy...", "Sleepy!", and "A black eye" often appear as his nicknames. He said,

"I am an engineer in the R \&B department. I work in an office for more than 10 hours every day. Each morning, I do not have the energy to do something. I feel so tired. I should find something to wake me up. Changing nicknames temporarily shifts my headache away."

For categories one and three, when online friends responded to participants' self-defined nicknames, their discussions were in the same as categories one and two showed in the theme 4. As for categories two and four, partic ipants' online friends often expressed concern about what happened to participants. For example, P2 said, "When my online friends identified my negative nicknames, they would ask me the reasons and then say something to comfort me." After conversing with online friends, partic ipants considered that their feeling were better.

\section{Theme 6: Tone Decided by Mood}

Mood influenced the tone of participants' self-defined nicknames. However, this rule is only applicable to the nicknames identified in the Theme5. When participants were in a good mood, their nicknames which contain emotional words would convey joyous feeling. For instance, "Happy," "Ha," and "Ya" often appeared in P2's nicknames. In contrast, while the mood of partic ipants turned angry or sad, emotional words appearing in the nicknames seemed to evoke sympathy. In this case, P6 broke his relationship with his girlfriend recently. The nickname, "Rainy day...does the sky cry for me??", showed his sadness. He said, "At that time, I really felt sad. I wanted to vent my feeling." However, when participants were in a bad mood, they would avoid using vulgar words as emotional words. P4 said, "It is rude to use dirty language." Similarly, P3 said, "Even though I am in a bad mood, I will avoid us ing dirty words in my nicknames."

In addition to emotional words, special symbols are used for emphasizing the tone of the nicknames. Like essay writing, "!" and "?" are often used for emphasizing the meaning of nicknames. Special symbols, such as " $\square$ " and "^_^", replace the purpose of emotional words. P7 once used the symbol ">_<" in her nicknames. She said, "A picture can say thousand words. The symbol I used is similar to the picture. It can express my feeling very well."

\section{Theme 7: Polarized Reaction}

Although all partic ipants knew that their nicknames were recorded, most of them were still surprised with the change rate results. The high change rate exceeds their expectations. P12 said, "Wow! I did not know I changed the nicknames so many times." Similarly, P2 said, "I do not care how many times I change the nicknames. But the high change rate really surprises me."

However, other participants took the high change rate for granted. They had been prepared for the result. P1 said, "I like to use nicknames to vent my feelings every day. The number you told me makes sense for me." Because of the data collection method in this study, one participant even doubted the result. P10 said, "I do not believe the number you told me. Sometimes, I change nicknames more than twice a day. My change rate should be higher than the number you told me." 


\section{Theme 8: Caring about Online Friends}

From Theme 2 to Theme5, participants' online friends would respond to the ir defined nicknames. Likew ise, partic ipants would also exhibit the same behavior when they recognized online friends' changed nicknames. They considered responses to be a social activity in a daily life. Caring about online friends is their responsibility. P11 said, "I pay attention to the ir nicknames. I care about them. I want to know more about them." P3 also expressed concern for her online friends, but she only responded to her close friends. She said, "Responding to someone you are not familiar with is very strange. When I send messages to my close friends, they feel I care about them. It is a good way to manage the relationship." In contrast to $\mathrm{P} 3, \mathrm{P} 12$ responded to any interesting nicknames regardless of relationships with online friends. He said, "When I see something interesting, I will send messages to my online friends. I remember; I also respond to someone I am not familiar with."

Two types of nicknames from online friends attract participants' attention. First, participants responded to the nicknames which make sense to them. When identifying these nicknames, participants sent messages which contain personal experiences or opinions. P2 said, "It is a good chance to converse with online friends. Their changed nicknames serve as a talking point. I often share my opinions during discussion." The other type, ambiguous nicknames, provokes partic ipants' interest. Participants are eager to seek answers. P1 said, "I remember one of online friends' nicknames is 'idiot.' I want to know why he used this word." P6 once misunderstood his online friend's nickname. He stated,

"When I saw new baby in his nickname, I assumed his wife was pregnant. But after sending messages to him, I found that his wife was not pregnant. I totally misunderstood his nickname. The pregnant woman is his neighbor."

For some participants, caring about online friends has become a habit. When they log into the IM, their first action is to browse online friends' nicknames which gives a clear view of what is happening. Participants are addicted to this behavior. $\mathrm{P} 4$ did not provide a reason for the browsing addiction. He said, "It is my daily routine. I enjoy reading online friends' nicknames." P9 tried to expla in his behavior. He said," It is fun to see what happened to my online friends. I browse their nicknames in my office every morning. I can get an overview of activities my online friends are recently involved in." P7 can not resist browsing online friends' nicknames. She said,

'When I open the instant messenger program, I will browse online friends' nicknames first. Finding something special is the next step. But I also browse their nicknames when I feel lonely. Usually, I will browse more than seven times in one day."

\section{Theme 9: Behavior in Real Life}

Due to busy schedules on a daily basis, none of the participants used other electronic medium, such as a blog, to reveal their personal feelings publicly. "No time" and "Try it in the future!" are the most frequent excuses. Obviously, WLM is the only electronic channel on which participants' personally defined messages (i.e. nicknames) can be seen by other people (online friends).

In real life (face-to-face situation), some participants would not actively reveal personal feelings to friends (not online friends) unless their friends ask first. P4 said, "I do not actively tell my friends what happened to me, even my close friends. I am a passive responder." The other participants only actively reveal the ir feelings to close friends. P7 said, "I am afraid to reveal my feelings to acquaintances. It will be so embarrassing if they do not respond to what I said. So I only do that to my close friends." Compared to online behaviors, partic ipants all reported that they would not reveal as many feelings to friends in real life. 


\section{Discussion}

The purpose of this study is to find evidence of self-disclosure from online users' self-defined nicknames in an IM program (i.e. WLM). From 12 participants' experiences, apparently the name-display feature serves as a feelings vent through which online users attempt to publicly broadcast several specific messages to other people through WLM. Although the motive for defining nicknames is different from Theme 2 to Theme 5 , the meanings of nicknames convey partic ipants' feelings, thoughts, and experiences. Obviously, participants want to reveal themselves to other online friends. This self-expression behavior is consistent with the definition of self-disc losure (Derlega, 1993; Omarzu, 2000). Therefore, self-disclos ure behavior exists through the name-display feature in IM activities.

Even though this study only involved a limited number of participants, the type of self-defined nicknames is closely similar to Smale and Greenberg's (2005) findings. In their study, 444 online users' nicknames fall into three categories: identification, information about self and broadcast message. With respect to self-defined nicknames in this study, 12 participants' nicknames from Theme 2 to Theme 5 can fall into the latter two categories. In addition, all participants' nicknames can also fall into Jourard's (1971) six categories of self-disc losure topics: attitudes and opinions, tastes and interests, work, money, personality, and body. Participants disclosed those topics to achieve self-expression purpose (Derlegra, 1979; Omarzu, 2000).

Previous studies (Tanis, 2007; Tichon, 2003) showed that social support appears in cyberspace. In this study, social support occurred when participants identified other online users' nicknames. By responding to online friends' nicknames, participants expressed their concern. They cared about their friends and paid attention to the ir recent social activities. In addition to social support from one side, partic ipants' online friends also exhibited the same behavior. IM activities seem similar to an online community in which mutual social support forms. In terms of responding to someone's nicknames, interactive message broadcasting between participants and their online friends sustains the community (Etzioni, 1998). In other words, partic ipants revealed their nicknames for social validation, receiving feedback from online friends (Derlega, 1993). Compared to other studies (Barak, 2007; Joinson, 2001), however, whether or not reciprocity of self-disclosure exists needs further exploration.

Although partic ipants revealed their nicknames for self-disclosure purposes, they still had the ir scruples about defining the nicknames. Some participants employed the nicknames to provide a hint for specific online friends. However, the targeted people can not always understand the meaning of nicknames, nor did participants expla in the meaning. Participants seemed to disclose the nicknames to convey their unpleasant feelings and avoided a conflict with the targeted people. This finding confirms that those engaging in self-disclosure would not reveal messages that provoke threats (Derlega, 1993). In addition, regardless of the purpose of defining nicknames, participants avoided using inappropriate words in their nicknames. Revealing these words is regarded as an impolite behavior. Therefore, in order to create a certain desired impression, participants would manipulate the disc losing messages (Derlega, 1993).

In real life, some participants would not disclose their feelings to acquaintances. They avoided the possibility of embarrassing the ir friends (Derlega, 1993; Omarzu, 2000). In the IM, however, partic ipants actively disc lose their nicknames to online friends. The level of intimate relationship with online friends is not their concern. Obviously, the cyberspace behavior is not cons istent with real life behavior. Although participants can see their online friends in real life, they still prefer to vent feelings with self-defined nicknames in the computer-mediated medium. In other words, silent self-disc losure in verbal form is partic ipants' preference for cyberspace.

A number of findings in this study provide new understanding of self-disclosure in the IM. First, in order to emphasize the tone of the nicknames, participants liked to add special symbols to the 
nicknames. Special symbols serve as an extra tool to support the self-disclosure's purpose. Second, once participants revealed interesting nicknames, conversation between participants and their online friends would easily form. Disclosing interesting nicknames provokes further conversation. Third, self-defined nicknames can be used for a warning purpose. Like personal mottos, disclosing these nicknames gives participants rules on how to behave in a daily life. Fourth, compared to other computer-mediated media, participants perceive that the name-display feature could fulfill a disclosure goal more easily. Last, while most of participants discovered the name-display feature for self-disclosure by themselves, few participants adopted this feature from the influence of online friends.

\section{Conclusion}

Although this study confirmed the role of self-disclosure for a name-display feature at an instant messenger program, the characteristics of participants and sample size of the population lead to limitations of this study. For the characteristics, all partic ipants are Taiwanese adults. A cultural factor for self-disclosure in the IM may exist. Furthermore, participants are not currently school students. Motivational factors for disclosing nicknames may be different if participants are students. Considering the sample size, a limited number of participants neither can produce rich information about different categories of nicknames nor allow generalization of other social contexts.

Several findings in the study need further in depth exploration. First, all female participants tended to disc lose sentimental nicknames with the goal of complaining about something. Future studies can employ a quantitative approach to test the gender differences among self-disclosed nicknames. Second, when logging onto the IM, some participants demonstrated addictive behavior: browsing online friends' nicknames. Whether or not this behavior becomes the Internet addiction is worthy of follow-up analysis. Third, due to the nickname collection technique, this study did not record how long each nickname was kept. Future studies can develop a programming tool to measure the timeframe of each nickname kept on the IM program. Such process may provide an indicator of self-disc losure in practice. Last, this study confirmed the existence of self-disclosure in the name-display feature on the IM. Future studies may recruit hundreds of subjects to compare the results of this study with additional quantitative data.

\section{References}

Barak, A., \& Gluck-Ofri, O. (2007). Degree and reciprocity of self-disclosure in online foru ms. CyberPsychology \& Behavior, 10(3), 407-415.

Cameron, A. F., \& Webster, J. (2005). Unintended consequences of emerging communication technologies: Instant Messaging in the workplace. Computers in Human Behavior, 21, 85-103.

Cheuk, W. S., \& Chan, C. Y. (2007). ICQ (I seek you) and adolescents: A quantitative study in Hong Kong. CyberPsychology \& Behavior, 10(1), 108-114.

Creswell, J. W. (2007). Qualitative inquiry \& research design: Choosing among five approaches (2nd ed.). Thous and Oaks, California: Sage.

Derlega, V. J., Metts, S., Petronio, S., et al. (1993). Self-disclosure. Ne wbury Park, CA: Sage.

Derlegra, V. J., \& Grzelak, J. (1979). Appropriateness of self-disclosure. In G. J. Chelune (Ed.), Origins, patterns, and implications of openness in interpersonal relationships (pp. 151-176). San Francisco: Jossey-Bass.

Dietz-Uhler, B., Bishop-Clark, C., \& Howard, E. (2005). Formation of and adherence to a self-d isclosure norm in an online chat. CyberPsychology \& Behavior, 8(2), 114-120. 
Doster, J. A., \& Nesbitt, J. G. (1979). Psychotherapy and self-disclosure. In G. J. Chelune (Ed.), Origins, patterns, and implications of openess in interpersonal relationships (pp. 177-224). San Francisco: Jossey-Bass.

Etzioni, A., \& Etzioni, O. (1998). Face-to-face and computer-mediated co mmunities: A co mparative analysis. The Information Society, 15, 241-248.

Grinter, R. E., \& Palen, L. (2002). Instant messaging in teen life. Paper presented at the 2002 ACM Conference on Computer Supported Cooperative Work, November 16-20, New Orleans, Louisiana.

Hsueh, I. C. (2001). Taiwan BBS users' self-disclosure, inclination of self-presentation in plan file, and perception of the nickname. National Chiao Tung University, Hsinchu, Taiwan.

Joinson, A. N. (2001). Knowing me, knowing you: Reciprocal self-disclosure in Internet-based surveys. CyberPsychology \& Behavior, 4(5), 587-591.

Joinson, A. N., \& Paine, C. B. (2007). Self-disclosure, privacy and the Internet. In A. N. Joinson, K. Y. Mckenna, T. Postmes, \& U.-D. Reips, (Eds.), The Oxford handbook of Internet psychology. NY: Oxford University Press.

Jourard, S. M. (1971). Self-disclosure: An experimental analysis of the transparent self. NY: Wiley-Interscience.

Kang, S. (2007). Dise mbodiment in online social interaction: Impact of online chat on social support and psychosocial well-being. CyberPsychology \& Behavior, 10(3), 475-477.

Leung, L. (2004). Net-generation attributes and seductive properties of the Internet as predictors of online activities and Internet addiction. CyberPsychology \& Behavior, 7, 333-348.

Moore, M., \& Kearsley, G. (2005). Distance education: A systems view(2nd ed.). Belmont, CA: Thomson Wads worth.

Morse, J. M. (1994). Designing funded qualitative research. In N. K. Denzin, \& Y. Lincoln (Eds.), Handbook of qualitative methods. Newbury Park, CA: Sage.

Moustakas, C. (1994). Phenomenological research methods. Thous and Oaks, CA: Sage.

MSN Network in Taiwan. (2006).The number of MSN users reaches to 75 million. Retrieved May, 2007, fro $\mathrm{m}$ http://news.msn.com.tw/

Omarzu, J. (2000). A disclosure decision model: Determining how and when individuals will self-disclose. Personality and Social Psychology Review, 4(2), 174-185.

Qian H., \& Scott, C. R. (2007). Anonymity and self-d isclosure on weblogs. Journal of Computer-Mediated Communication, 12(4), 1428-1451.

Sedman, I. (2006). Interv iewing as qualitative research: A guide for researchers in education and the social sciences (3rd ed.). New York, NY: Teachers College Press.

Smale, S., \& Greenberg, S.(2005). Broadcasting information via display names in instant messaging. Paper presented at the 2005 International ACM SIGGROUP Conference on Supporting Group Work, November 6-9, Sanibel Island, Florida, USA.

Tai, K.-F. (2007). Applying Windows Live Messenger into English teaching: A case study of a mixed-level class. Retrieved November 18, 2007, from http:// www.usc.edu.tw/college/afl/conference-agenda.html

Tanis, M. (2007). On line social support groups. In A. N. Joinson, K. Y. Mckenna, T. Postmes, \& U.-D. Reips (Eds.), The Oxford handbook of Internet psychology (pp. 139-153). New York: Oxford University Press.

Tichon, J. G., \& Shapiro, M. (2003). The process of sharing social support in cyberspace. CyberPsychology \& Behavior, 6(2), 161-170.

Van Dongena, W. S. (2007). Forensic artifacts left by Windows Live Messenger 8.0. Digital Investigation. 14(2), 73-87. 
Van Manen, M. (1997). Researching lived experience: Hu man science for an action sensitive pedagogy (2nd ed.). London, Ontario: The Althouse Press.

$\mathrm{Wu}$, C. - H. (2007). A ban on the use for instant messengers. Retrieved November 02, 2007, from http://news.yam.com/tvbs/politics/200707/20070731549733.html

Yam Portal (2005). Online survey for user behavior. Retrieved November 11, 2007, from http://survey.yam.com/survey2004/index.html

Yu, S. (2003). Status of service and market for instant messengers in Taiwan. Retrieved November 29, 2007, from http://www.insightxplorer.com/news/news $09 \quad 23 . \mathrm{html}$

\section{Appendix (Interview Guide)}

The intent of eight questions was to elic it participants' lived experiences of using the name-display feature in the instant messenger. These questions are: (1) After installing the instant messenger, how did you know the name-display feature? Did any situations force you to begin using this feature? (2) What are the meanings of written words displayed in your nicknames? What is your purpose of changing these nicknames? (3) How do you decide the tone of written statements in your nicknames? (4) Did any things happen to you after you changed the nicknames? (5) In addition to verbal descriptions, what other symbols would you use in the nicknames? Why did you use these symbols? (6) When you recognized your online friends' changed nicknames, what were your reactions? (7) How do you feel about your high change rate for nicknames? (8) Would you reveal those feelings, which relate to the meaning of nicknames, to someone else in daily life? Or would you reveal your feelings in the electronic media (e.g. Blog)?

\section{Biographies}

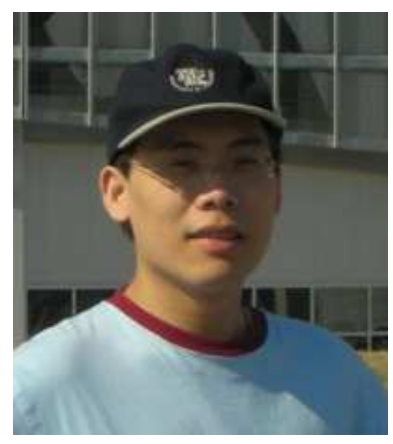

Pao-Nan Chou received his B.S. in Electronic Engineering and M.S. in Workforce Education and Development from National Taipe i University of Technology, Taiwan. He also received his M.Ed. in Instructional Systems from The Pennsylvanian State University, USA. Currently, he is $\mathrm{PhD}$ candidate in Instructional Systems at The Pennsylvanian State University.

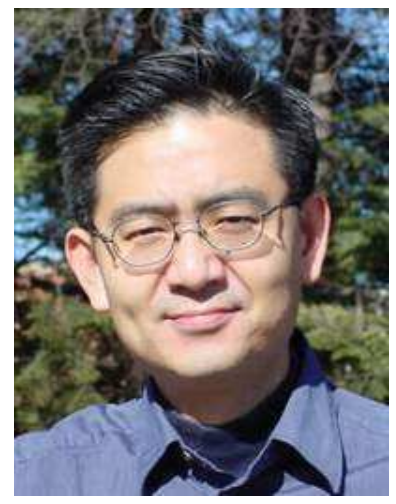

Wei-Fan Chen received his B.S. in Information and Computer Engineering in 1993, from Chung Yuan Christian University, Taiwan. He received his M.Ed. and Ph.D. in Instructional Systems in 1999 and 2002, respectively, both from The Pennsylvania State University, USA. He is currently an Assistant Professor of Information Sciences and Technology at The Pennsylvania State University. Dr. Chen's research and teaching interests include cognitive and information sciences and technology as related to learning. 